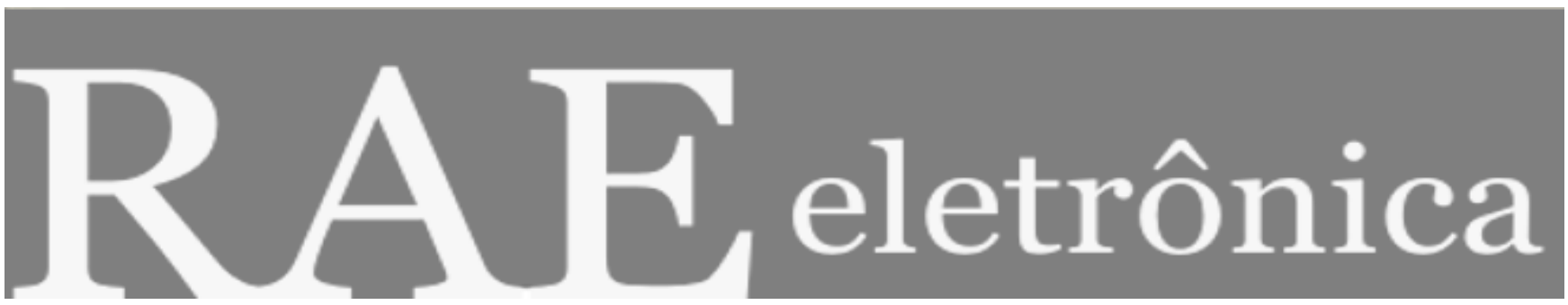

\title{
PROBLEMAS E MÉTODOS DECISÓRIOS DE LOCALIZAÇÃO DE EMPRESAS
}

Por:

\section{Fábio Ricardo Loureiro Sato}

RAE-eletrônica, Volume 1, Número 2, jul-dez/2002.

http://www.rae.com.br/eletronica/index.cfm?FuseAction=Artigo\&ID=1462\&Secao=EMPRESA\%20JR $\&$ Volume $=1 \&$ Numero $=2 \& A n o=2002$

CCopyright, 2002, RAE-eletrônica. Todos os direitos, inclusive de tradução, são reservados. É permitido citar parte de artigos sem autorização prévia desde que seja identificada a fonte. A reprodução total de artigos é proibida. Os artigos só devem ser usados para uso pessoal e nãocomercial. Em caso de dúvidas, consulte a redação: redacao@rae.com.br.

A RAE-eletrônica é a revista on-line da FGV-EAESP, totalmente aberta e criada com o objetivo de agilizar a veiculação de trabalhos inéditos. Lançada em janeiro de 2002, com perfil acadêmico, é dedicada a professores, pesquisadores e estudantes. Para mais informações consulte o site www.rae.com.br/eletronica.

RAE-eletrônica

ISSN 1676-5648

(C)2002 Editora: Fundação Getulio Vargas - Escola de Administração de Empresas de São Paulo.

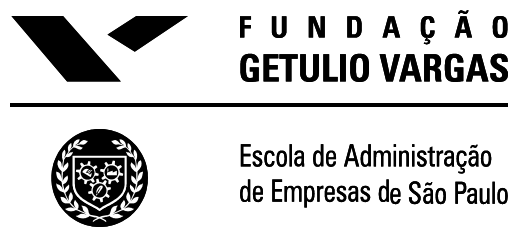




\title{
PROBLEMAS E MÉTODOS DECISÓRIOS DE LOCALIZAÇÃO DE EMPRESAS
}

\section{Fábio Ricardo Loureiro Sato}

Mestrando em Administração de Empresas pela FGV- EAESP.

E-mail:fsato@gvmail.br

Endereço: Av. Nove de Julho 2029 - 5 Andar - PROHASA - São Paulo - SP, 01313-902

Interesses de pesquisa: Administração de Empresas, Administração Hospitalar e Sistemas de Saúde, Administração Mercadológica.

\section{RESUMO}

A tomada de decisão é certamente a atividades mais freqüente que encontramos dentro das empresas. Algumas dessas decisões são de grande relevância, outras nem tanto. A determinação da localização é certamente uma das escolhas que tem maior impacto nos resultados. Apesar disso, os tomadores de decisões das empresas ainda não utilizam métodos científicos na hora de escolher a localização de suas instalação. Dessa forma, o objetivo deste artigo é apresentar alguns dos problemas enfrentados e os métodos hoje disponíveis que podem ser utilizados nesses momentos nas empresas.

\begin{abstract}
The decision process is on of the most frequent actitivites that we can be found in the companies. Some of this decisions are very important, other, not so much. The determination of the localization of a firm is one of the decisions that has the biggest impact in the results. Althought all this arguments, the responsible people for this decisons in the companies do not use a cientifical method when deciding where to install theirs units. In this way, the aim of this article is presenting some of the problems faced and the methods avaliable nowadays that can be used in this critical moments in the companies.
\end{abstract}

\section{PALAVRAS-CHAVES}

Métodos decisórios, localização de empresas, logística, supply chain, clusters.

\section{KEY WORDS}

Decision methods, companies localization, logistics, supply chain, clusters. 


\section{INTRODUÇÃO}

Uma das decisões mais importantes que uma empresa deve tomar, seja ela do setor produtivo ou de serviços, refere-se à sua localização. Esta é definida como a "localização geográfica de uma operação relativamente aos recursos, a outras operações ou clientes com os quais a empresa interage". (SLACK et al., 1997)

Até pouco tempo atrás, essa decisão quanto à localização dependia quase que totalmente do feeling pessoal do CEO da empresa, sem a adoção de nenhum método científico. (DIAS, 1993) É claro que este feeling pessoal não era algo aleatório, mas sim uma derivação de anos de experiência no setor e relacionamentos com clientes e fornecedores.

No mundo globalizado em que vivemos atualmente, essa decisão ficou ainda mais difícil, frente ao enorme número de mercados fornecedores e consumidores com os quais as empresas interagem. Por isso, muitos autores começaram a pesquisar métodos científicos que pudessem auxiliar na tomada de decisão quanto à localização de novos empreendimentos. (BRANDEAU e CHIU, 1989)

Entre esses estudiosos, Michael Porter teve importante colaboração nos últimos anos, através de seus trabalhos a respeitos dos clusters, também chamados de agregados ou agrupamentos geográficos por alguns autores brasileiros.

Desse modo, o objetivo deste artigo será mostrar alguns dos problemas encontrados durante a determinação da localização, as variáveis que impactam sobre as decisões, os métodos atualmente existentes e finalmente, a influência dos clusters sobre essas decisões.

\section{OS PROBLEMAS NA DETERMINAÇÃO DA LOCALIZAÇÃO}

BALLOU (2001) classifica os problemas encontrados na determinação da localização em cinco categorias: força direcionadora, número de instalações, escolhas discretas, grau de agregação de dados e horizonte de tempo.

Quanto à força direcionadora, o autor afirma que dependo do setor que uma determinada empresa atua, certos fatores são mais importantes que outros no momento de decisão de localização, e estes acabam direcionando as empresas. Por exemplo, no setor de varejo, a proximidade dos clientes é muito mais importante do que para o setor industrial, pois no primeiro caso os clientes, que são os consumidores finais da cadeia produtiva, precisam se deslocar até a empresa, e o inverso ocorre para as indústrias. No caso de uma prestadora de serviço (hospital, video-locadora, loja de consertos,...), a acessibilidade ao local pode ser o fator principal da localização, especialmente quando as receitas e os custos não são determinados com facilidade. (COBRA, 1994)

Também é muito diferente a determinação de uma única unidade produtiva, ou a determinação de várias unidades. A localização de instalação única evita a necessidade de considerar entre as unidades as forças competitivas de demanda, efeitos de consolidação de estoque, custos de instalações, proximidade entre mão-de-obra especializada para cada linha de montagem, entre outros. Os custos de transporte são a consideração primária nestes casos. 
Em relação às escolhas discretas, estes estão mais relacionados às localizações de instalações múltiplas, pois inicialmente são selecionadas várias regiões potenciais ao recebimento dos investimentos da empresa, e dessas, selecionadas as melhores, em função da razoabilidade. Claro que essa escolha não é fácil, pois toda região possui vantagens e desvantagens em relação às suas concorrentes.

Um outro problema está ligado ao grau de agregação de dados. Quando vamos tomar a decisão de localização, temos uma infinidade de dados, o que obriga quem irá decidir a agregar os dados para ter um parâmetro melhor de decisão. A questão é exatamente como agregar esses dados para continuar a ter dados fidedignos.

Por fim, precisamos levar em consideração a questão do tempo. O método a ser utilizado é estático ou dinâmico. Os métodos estáticos selecionam localizações em dados de um único período de tempo, tal como um ano. Entretanto, os planos de localização podem cobrir muitos anos de uma só vez, especialmente se as instalações representam um investimento fixo e os custos de movimentação de um local para outro são altos. (BALLOU, 2001)

\section{VARIÁVEIS QUE IMPACTAM NA DECISÃO DE LOCALIZAÇÃO}

Classicamente são duas as variáveis que acabam influindo nesse processo: as alterações na demanda de bens e serviços e as alterações na oferta de insumos para a operação. (SLACK et al., 1997; LONGENECKER et al., 1997)

Impactando sobre a oferta de insumos, temos os custos da mão-de-obra, da terra, da energia, dos transportes e outros fatores da comunidade. Com relação à demanda, influenciam a qualificação da mão-de-obra, a adequação do local, a imagem da empresa e a conveniência para os clientes, como rapidez e confiabilidade. (SLACK et al., 1997)

MacCORMACK et al (1994) dividiu essas variáveis em fatores qualitativos e quantitativos. Para o autor, os fatores qualitativos envolvidos seriam a infra-estrutura local, a educação e qualificação dos trabalhadores, as exigências de conteúdo do produto e a estabilidade política/econômica.

A infra-estrutura local necessária para dar suporte a uma operação de manufatura poderia ser dividida em duas amplas categorias: a institucional e a de transporte. Com a demanda cada vez maior para que as empresas possuam linhas produtivas flexíveis, que atendam as necessidades dos clientes de forma customizadas, elas também precisam instituições e fornecedores flexíveis e sensíveis. A rede de transporte precisa ser eficiente e confiável. Por exemplo, que empresa arriscaria colocar sua linha de produção num local onde não há como chegar insumos e escoar sua produção?

Os processos atuais de manufatura estão cada vez mais sofisticados, e por isso, demandam uma força de trabalho altamente educada e equipada com uma grande variedade de qualificações. Foi justamente por possuir vantagem competitiva em educação e qualificação dos seus trabalhadores, que os países dos chamados "Tigres Asiáticos" acabaram atraindo um grande número de indústrias transnacionais para o seu território, além do custo do trabalhador ser bem menor do que em outros países ditos desenvolvidos. (SENE e MOREIRA, 2000)

As exigências de conteúdo do produto indicam o percentual mínimo do produto que deve ser produzido dentro dos limites de um país, a fim de que o produto seja vendido no mesmo. Esse instrumento de política econômica garante o emprego na comunidade local, enquanto reduz o déficit comercial do país. DAVIS et al (2001) cita o exemplo das Filipinas, que obriga que todos os automóveis comercializados 
no país sejam produzidos internamente. Isto também ocorreu no Brasil, principalmente na década de 80, com a Lei do Similar Nacional, que proibia a importação de certos produtos a fim de proteger a indústria nacional. (LACERDA et al.,2000).

A estabilidade de uma região refere-se ao número e à intensidade de flutuações políticas e econômicas que podem lá ocorrer. Quanto mais estável é um país, maior será a capacidade do mesmo atrair investimentos. Este argumento foi muito utilizado pela equipe econômica para justificar que o déficit em conta corrente brasileiro era temporário logo após a implantação do Plano Real. (OLIVEIRA, 1996)

Em relação aos fatores quantitativos, MacCORMACK et al. (1994) incluem os custos de mão-de-obra, custos de distribuição, custos de instalação e taxas de câmbio.

Os custos de mão-de-obra variam drasticamente, tanto entre países, como entre regiões dentro de uma mesma nação. Uma das razões para a saída de muitas empresas siderúrgicas do $\mathrm{ABC}$ paulista foi justamente o elevado custo da mão-de-obra da região, em comparação com outras regiões dentro e fora do Estado de São Paulo. Entretanto, é preciso levar em consideração também que embora o custo de mão-de-obra em muitas áreas seja muito baixo, os trabalhadores dessas mesmas regiões não têm, freqüentemente, qualificações e educação adequadas.

Com a globalização e a dispersão territorial cada vez maior dos clientes, os custos de distribuição aumentam de importância. Além dos custos propriamente ditos, é também preciso considerar os tempo de entrega. (DAVIS et al., 2001)

Os custos de Instalação ganharam destaque no país nos últimos anos devido à guerra fiscal entre os Estados. A fim de atraírem empresas, os governos estaduais passaram a oferecer terrenos gratuitos, isenção de impostos, incentivos fiscais, entre outras vantagens, o que reduz os custos de instalação da empresas.

As taxas de câmbio também podem ser um importante fator de atração de investimentos diretos. A desvalorização das moedas locais, como ocorreu no Japão e no Brasil, torna os produtos desses países mais competitivos no exterior, o que aumenta as exportações dos mesmos. Em virtude desse fato, muitas empresas transnacionais acabaram instalando-se ou aumentando a sua capacidade produtiva nesses países com dólar valorizado. (FRANCO, 1998)

\section{BREVE HISTÓRICO SOBRE LOCALIZAÇÕES}

A maioria das teorias iniciais sobre localização foram postuladas por economistas e geógrafos. A grande maioria deles abordavam a questão do custo de transporte na determinação da localização. (PUU, 1997)

THÜNEN (in BALLOU, 2001) afirmou que o aluguel máximo, ou lucro, que qualquer empresa poderia pagar pela terra era a diferença entre o preço para as mercadorias no mercado e o custo do transporte dessas mercadorias para o mercado.

O papel que as matérias-primas desempenham no processo de produção e como elas afetam a localização foi discutido por Alfred Weber (in FRIEDRICH, 1929) Ele observou que alguns processos, como o refino do açúcar, são perdedores de peso. Isto é, a soma do peso das matérias-primas é maior que o peso dos produtos acabados. O peso é perdido no processo devido a subprodutos não-utilizáveis. 
Consequentemente, para evitar embarques de subprodutos para o mercado, tais processos são retirados das fontes de matérias-primas de forma a minimizar os custos de transporte.

Por outro lado, os processos podem ser ganhadores de peso. Isto ocorre quando as ubiqüidades, que incluem o ar e a água, entram no processo. Portanto, para minimizar os custos de transporte, tais processos devem localizar-se tão próximo quanto possível aos mercados. Se não houvesse mudança de peso entre matérias-primas e produtos acabados, o local a ser escolhido era livre, podendo estar próximo aos fornecedores ou consumidores.

Complementando esta última afirmação de Weber, HOOVER (1957) observou que as taxas de transporte crescem com a distância. Para minimizar os custos de transporte de entrada mais saída nos quais eles são a força de localização dominante, um instalação localizada na fonte de matéria-prima ou no mercado terá o mínimo custo de transporte.

\section{MÉTODO ATUAL DE LOCALIZAÇÃO DE INSTALAÇÃO ÚNICA}

Atualmente, o método mais utilizado para localização de uma planta única, terminal, armazém ou prestador de serviço, é o do chamado centro de gravidade exato, método de grade ou método centróide. (DAVIS et al, 2001; BALLOU, 2001; SLACK et al., 1997)

Para SLACK et al (1997), esse método é baseado na idéia que todas as localizações possíveis têm um "valor" que é a soma de todos os custos de transporte de e para aquela localização. A melhor localização, a que minimiza custos, é representada pelo que, em uma analogia física, seria o centro de gravidade ponderado de todos os pontos de e para onde os bens são transportados. Desse modo, as variáveis aqui são a taxa do transporte e o volume dos pontos.

Procura-se minimizar a soma do volume em um ponto multiplicado pela taxa do transporte para enviar ao ponto multiplicado pela distância ao ponto que é o custo total do transporte. Ou seja:

Min TC $=\sum$ Vi.Ri.di

Onde: $\mathrm{TC}=$ Custo Total do transporte

$\mathrm{Vi}=$ Volume no ponto $\mathrm{i}$

$\mathrm{Ri}=$ Taxa do transporte ao ponto $\mathrm{i}$

di = Distância ao ponto i da instalação a ser localizada

A localização da instalação é encontrada resolvendo duas equações para as coordenadas de localização (X' e Y'):

$\mathrm{X}^{\prime}=\sum \mathrm{Vi} . \mathrm{Ri} . \mathrm{Xi} / \mathrm{di}$

$\sum \mathrm{Vi} . \mathrm{Ri} / \mathrm{di}$

$\mathrm{Y}^{\prime}=\sum$ Vi.Ri.Yi/di

\section{$\sum \mathrm{Vi} . \mathrm{Ri} / \mathrm{di}$}

Onde: $X^{\prime}$ e $Y^{\prime}=$ Coordenadas da instalação localizada

$\mathrm{X}$ e $\mathrm{Y}=$ Coordenadas da fonte e da demanda 
Certamente este método, assim como outros utilizados para a determinação de localização, como o Método de aproximações, (WESOLOWKY e LOVE, 1972) possui muitas simplificações, porém, ele não deixa de ser uma forma de auxílio na tomada de decisão.

BALLOU (2001) afirma que as principais simplificações desse modelo são:

Os volumes de demanda são freqüentemente presumidos estando concentrados em um ponto, quando, de fato, eles são gerados de vários pontos de clientes que estão dispersos por uma ampla área; só são levados em consideração os custos variáveis, deixando-se de lado os custos fixos; presume-se que as rotas são todas em linha reta, o que raramente ocorre; é um modelo estático, que deixa de refletir mudanças futuras nas receitas e custos.

\section{MÉTODO DE LOCALIZAÇÃO DE VAREJO E DE SERVIÇO}

Os centros de varejo e de serviço são os pontos de estocagem final em uma rede de distribuição física. A análise da localização para esses pontos com freqüência deve ser altamente sensível às receitas e aos fatores de acessibilidade em vez de fatores de custos, tão importantes para localização de fábricas e armazéns. Proximidade da concorrência, composição da população, padrões de trânsito de clientes, proximidade de lojas complementares, disponibilidade de estacionamento, entre outros, são apenas alguns dos muitos fatores que podem influenciar a localização do varejo ou do serviço. (LAS CASAS, 2000).

Para os setores de varejo e de serviço, utilizamos basicamente dois métodos: o da lista de verificação ponderada e o modelo de interação espacial. A lista de verificação ponderada, também chamada de Sistema de estimativa de Fatores por DAVIS et al. (2001), é um método no qual é formada uma matriz ponderada de fatores de localização, como alguns acima citados, e que são classificados por locais potenciais. Um índice, que é a soma dos pesos dos fatores multiplicados pela classificação dos fatores, seria a classificação total para o local. Os locais com altos índices teriam preferência. (BALLOU, 2001; LEVY, 2000)

Apesar da simplicidade, este modelo não é o mais utilizado, perdendo este posto para o Modelo de Interação Espacial. Este modelo é derivado da Lei de Reilly da gravitação do varejo, modificada posteriormente por Paul Converse, dando origem à Lei de Converse (DIAS, 1993)

Para REILLY (1931), “duas cidades atraem negócios de um ponto intermediário na razão direta do tamanho de suas populações e na razão inversa do quadrado da distância das duas a esse ponto intermediário". Ou seja:

$(\mathrm{Ba} / \mathrm{Bb})=(\mathrm{Pa} / \mathrm{Pb})=(\mathrm{Db} / \mathrm{Da})^{2}$

Onde: $\mathrm{Ba}$ e $\mathrm{Bb}=$ Quantidade de negócios que a cidade $\mathrm{A}$ e $\mathrm{B}$ atraem para si, de um ponto intermediário;

$\mathrm{Pa}$ e $\mathrm{Pb}=$ População da cidade A e B;

$\mathrm{Da}$ e $\mathrm{Db}=$ Distância da cidade $\mathrm{A}$ e $\mathrm{B}$ ao ponto intermediário.

Converse alterou a fórmula de Reilly, criando o chamado "ponto de indiferença". Esse ponto de indiferença seria o ponto no qual os consumidores seriam indiferentes no que concerne a comprar em qualquer das duas cidades. (DIAS, 1993) A fórmula de Converse é a seguinte: 
$\mathrm{Dab}=\mathrm{d} / 1+\sqrt{\mathrm{Pb} / \mathrm{Pa}}$

Onde: $\mathrm{Dab}=$ Ponto de indiferença medido em quilômetros a partir da cidade $\mathrm{A}$ em direção a $\mathrm{B}$;

$\mathrm{d}=$ Distância entre A e B;

$\mathrm{Pa}$ e $\mathrm{Pb}=$ População das Cidades A e B.

A esses conceitos, David Huff, em 1966, acrescentou as variáveis de "massa" ou "variedade" oferecidas pelos varejistas, como a metragem quadrada da loja, número de itens em estoque e níveis de estoque mantidos, criando o Modelo de interação espacial. A distância da fórmula foi substituída pelo tempo de deslocamento dos clientes até a loja. (GHOSH e McLAFFERTY, 1987). Dessa forma, o modelo passou a ser expresso como:

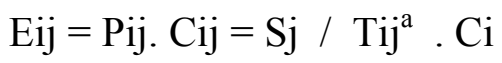

$$
\sum \mathrm{j} \cdot \mathrm{Sj} \cdot \mathrm{Tij}^{\mathrm{a}}
$$

Onde:

Eij = Demanda esperada do centro populacional i que será atraído para a localização de varejo j;

Pij = Probabilidade dos clientes do centro populacional i viajarem até a localização de varejo j;

$\mathrm{Cij}=$ Demanda dos clientes no centro populacional $\mathrm{i}$;

$\mathrm{Sj}=$ Variáveis de atração de clientes (Tamanho da loja, níveis de estoques, estacionamento,...);

Tij $=$ Tempo de viagem entre o centro populacional i e o varejo $\mathrm{j}$;

n = Número de localizações de varejo j;

a = Parâmetro estimado empiricamente (Fator de ajuste entre o que o modelo estima, e o que empiricamente observamos).

Esse modelo de Huff é um modelo básico para a interação espacial. Novos modelos vêm sendo desenvolvidos e testados, envolvendo, por exemplo, a teoria dos jogos (MOORTHY, 1985), com um nível de complexidade ainda maior. Porém, novamente afirmo que não queremos que esses modelos sejam a forma definitiva de se determinar o local onde será localizado o novo empreendimento, mas apenas um instrumento de auxílio para a empresa na tomada dessa decisão. O feeling pessoal do CEO, ainda que o método mais antiga de determinação de localização, ainda é considerado de relevante importância nesses casos.

\section{O IMPACTO DOS CLUSTERS SOBRE AS DECISÕES DE LOCALIZAÇÃO DAS EMPRESAS}

Atualmente, quando a economia de um determinado país é analisada, principalmente tendo em vista a competitividade dessa região, procuramos não mais adotar um método que enfoca empresas, setores ou áreas como a industrial ou de serviços, mas sim os aglomerados que formam a estrutura industrial do país, também denominados de clusters. 
Esses aglomerados, cujas origens iniciaram-se juntamente com o comércio na Baixa Idade Média, entre os séculos XII e XIII (MELLO e AMAD COSTA, 2001), começaram a serem estudados por Alfred Marshall, em Principles of Economics, publicado em 1890. (PORTER, 1999). Durante os cinquenta primeiros anos do século passado, essa parte de economia geográfica foi muito estudada, sendo deixada de lado em meados do mesmo século para dar lugar aos estudos da chamada Teoria Econômica Neoclássica. Só mais recentemente este tema passou a ganhar maior importância. (KRUGMAN, 1991)

$\mathrm{Na}$ literatura gerencial, a questão da localização da empresas está muito mais ligada aos problemas de diversidade cultural do que com as vantagens e desvantagens do processo. Com a ideologia da globalização, isto foi cada vez mais deixado de lado, pois as fronteiras entre nações estariam sendo demolidas. Foi Michael Porter, professor da Harvard Bussiness School, que acabou retomando novamente a discussão da importância dos clusters para as empresas, com a publicação de artigos e livros como "A Vantagem Competitiva das Nações"(1989) e "Competição"(1999).

Essa nova abordagem dada pelo autor acima citado é inovadora no sentido que desloca parte da responsabilidade pela vantagem competitiva da empresa para o lado externo, ou seja, para a localização de suas unidades de negócio.

Para Porter, um Cluster poderia ser definido como "um agrupamento geograficamente concentrado de empresas inter-relacionadas e instituições correlatas numa determinada área, vinculadas por elementos comuns e complementares" (PORTER, 1999).

Mas por que as empresas estão cada vez mais se concentrando nesses pólos de desenvolvimento? Principalmente porque a concorrência moderna depende da produtividade, não do acesso a insumos ou da economia de escala de empreendimentos isolados. A produtividade, por sua vez, depende de como as empresas concorrem, não dos campos em que concorrem; e o grau de sofisticação das empresas é fortemente influenciado pelas condições do ambiente empresarial local. As empresas não podem empregar técnicas avançadas de logísticas, por exemplo, sem uma infra-estrutura de transporte de alta qualidade. E também não podem concorrer de forma eficaz oferecendo serviços sofisticados se não tiverem funcionários bem treinados. (PORTER, 1998)

Infelizmente, muitos desses fatores são deixados de lado pelos métodos clássicos de determinação da localização das novas empresas, como os apresentados acima.

Os aglomerados influenciam a competição de três maneiras: primeiro, pelo aumento da produtividade das empresas ou setores componentes; segundo, pelo fortalecimento da capacidade de inovação e, em conseqüência, pela inovação da produtividade; terceiro, pelo estímulo à formação de novas empresas, que reforçam a inovação e ampliam o conglomerado. (PORTER, 1998).

Michael Porter enumera de maneira excepcional em seu livro "Competição" (1999) os motivos para as empresas cada vez mais se implantarem em aglomerados industriais, que são respectivamente:

Acesso a insumos e a pessoal qualificado - A localização no interior de um aglomerado tem condições de proporcionar acesso a insumos especializados de melhor qualidade ou de custo mais baixo.

Acesso à informação - As informações técnicas, de mercado e sobre outras áreas especializadas se acumulam dentro do aglomerado. $\mathrm{O}$ acesso a essas informações é de melhor qualidade e a custos 
inferiores no interior do aglomerado, permitindo que as empresas participantes aumentem a produtividade e se aproximem da fronteira da mesma.

Complementariedade - $\mathrm{O}$ aglomerado contribui para o aumento da produtividade, não apenas através da aquisição e montagem de insumos, mas também pela facilitação das complementariedades entre as atividades dos diferentes participantes.

Acesso a instituições e a bens públicos - Os aglomerados tornam os gastos públicos muito mais eficientes, pois muitos agentes poderão desfrutar desses investimentos localizados em poucos lugares.

Incentivos e mensuração do desempenho - A rivalidade com os competidores locais exercem um forte efeito estimulante, em vista da facilidade de comparação constante e uma vez que os rivais da mesma localidade enfrentam circunstâncias gerais mais ou menos semelhantes.

Além desses fatores acima citados, existem outros que estimulam a vinda de novas empresas para os clusters. Por exemplo, os aglomerados proporcionam maiores incentivos à entrada, através de melhores informações sobre as oportunidades existentes. Os indivíduos que trabalham dentro ou nas proximidades percebem com maior facilidade as lacunas a serem preenchidas nos produtos, nos serviços ou nos fornecedores. Com base nesses insights, esses indivíduos mais rapidamente deixam as empresas estabelecidas para iniciar novos negócios, com o objetivo de preencher essas colunas.

Soma-se a isso o fato das barreiras de entrada serem baixas, pois os insumos necessários à montagem de uma nova empresa são facilmente adquiridos nesses aglomerados. Os investidores e as instituições financeiras também exigem um prêmio de risco e um spread menor.

Portanto, a teoria dos aglomerados mostra que a escolha da localidade deve considerar o potencial de produtividade total, e não apenas os custos dos insumos e a carga tributária. $\mathrm{Na}$ localização das atividades, o objetivo é o custo total baixo. Todavia, as localidades com salários baixos e impostos reduzidos geralmente carecem de uma infra-estrutura eficiente, de disponibilidade de fornecedores, de manutenção oportuna e de outras condições oferecidas pelos aglomerados. Os custos de logística e de introdução de novos modelos às vezes são substanciais. Muitas empresas descobriram que essas desvantagens de produtividade às vezes mais do que neutralizavam outras possíveis vantagens limitadas.

Assim, a localização num aglomerado existente ou em desenvolvimento geralmente envolve custos sistêmicos totais mais baixos e uma capacidade de inovação amplamente melhorada.

PORTER(1998) salienta os aspectos positivos de se transferirem grupos de atividades interligadas para o mesmo lugar em vez de espalhá-las entre inúmeros estados e países. Afirma o autor que dessa forma, "reduz-se o custo total dos sistemas, dinamiza-se o compartilhamento das informações internas, facilita-se a difusão da inovação, cria-se massa crítica para a infra-estrutura e as instalações da empresa e lança-se raízes mais profundas nos aglomerados locais, aumentando a capacidade de aproveitar externalidades e extravasamentos".

\section{CONCLUSÃO}


Determinar a localização de uma empresa nunca foi uma decisão simples para os administradores. Antes, a escolha da localização era feita baseada mais no subjetivismo do que em qualquer tipo de teoria objetiva.

Entretanto, há quase um século, a teoria sobre a localização das empresas vem recebendo grandes contribuições de diversos autores, tornando-a extremamente técnica, por exemplo, com a Teoria do Centro de Gravidade para instalações industriais únicas, ou o Método de Interação Espacial, para o mercado de varejo e de prestação de serviços.

Infelizmente, muitas dessas teorias acabaram focalizando-se exclusivamente em custos de transporte, distância entre os pontos de demanda e oferta, tamanho de mercados consumidores, entre outras variáveis, e acabaram deixando de lado outros fatores importantes, como infra-estrutura, facilidade de acesso a insumos e inovações, ambiente competitivo e cooperativo entre empresas, entre outros, fatores esses de extrema importância numa economia competitiva como a que vivemos atualmente.

Para suprir essa lacuna, e justificar o crescimento dos grandes aglomerados atualmente, este artigo procurou apresentar também os principais pontos da teoria dos aglomerados (ou clusters) de Michael Porter, e seus impactos sobre a decisão de localização das empresas.

Para esse autor, as empresas atualmente procuram no momento de decidir onde se instalarem, locais competitivos e que possam aumentar a sua produtividade. Desse modo, analisam primeiramente os fatores que impactam sobre sua produtividade, como acesso a mão-de-obra e fornecedores, a informações especializadas, a atividades correlatas, a instituições e bens públicos, entre outros, que muitas vezes são deixadas de lado pelas teorias tradicionais de localização das empresas.

Portanto, a questão sobre a teoria da localização das empresas ainda não está fechada, e esperamos ter contribuído com esse artigo um pouco mais para a sua evolução.

\section{Artigo recebido em 19.05.2001. Aprovado em 06.06.2002}

\section{REFERÊNCIAS BIBLIOGRÁFICAS}

BALlOU, R. H. Gerenciamento da Cadeia de Suprimentos - Planejamento, Organização e Logística Empresarial. $4^{\text {a }}$ Ed. Porto Alegre: Bookman, 2001.

BRANDEAU, M. L.; CHIU, S. S. An Overview of Representative Problems in Location Research. Management Science, v. 35, n. 6, p. 645-674, Jun. 1989.

COBRA, M. Administração de Vendas. São Paulo: Editora Atlas, 1994.

DAVIS, M. M.; AQUILANO, N. J.; CHASE, R. B. Fundamentos da Administração da Produção. Porto Alegre: Bookman, 2001.

DIAS, S. R. Estratégia e Canais de Distribuição. São Paulo: Editora Atlas, 1993.

FRANCO, G. A Inserção externa e o desenvolvimento. Revista de Economia Política. V. 18, nº 3, JulSet 1998. 
FRIEDRICH, C. J. Alfred Weber's Theory of the Location of Industries. Chicago: University of Chicago Press, 1929.

GHOSH, A.; MCLAFFERTY, S. L. Location Strategies for Retail and Service Firms. Massachusetts: Heath, 1987

HOOVER, E. M. Location Theory and the Shoe and Leather Industries. Cambridge: Harvard University Press, 1957.

KRUGMAN, P. Trade and Geography. Massassuchets: MIT Press, 1986.

LACERDA, A. C. et al. Economia Brasileira. Organizadores: José Márcio Rego; Rosa Maria Marques. São Paulo: Saraiva, 2000.

LAS CASA, A. L. Marketing de Varejo. São Paulo: Editora Atlas, 2000.

LEVY, M. B. Administração de Varejo. São Paulo: Editora Atlas, 2000.

LONGENECKER, J, G,; MOORE, C. W.; PETTY, J. W. Administração de Pequenas Empresas. São Paulo: Makron Books, 1997.

MACCORMAK, A. D.; NEWMANN, L. I.; ROSENFELD, D. B. The new dynamics of global manufacturing site location. Sloan Management Review. p. 69-80, Summer 1994.

MELlO, L. I. A., AMAD COSTA, L.C. História Moderna e Contemporânea. São Paulo: Editora Scipione, 2001.

MOORTHY, K. S. Using Game Theory to Model Competition. Journal of Marketing. V. 22, p. 262$282,1985$.

OLIVEIRA, G. Brasil Real-Desafios da Pós Estabilização. São Paulo: Ed. Mandarim, 1996.

PORTER, M. A Vantagem Competitiva das Nações. São Paulo: Editora Campus, 1989.

PORTER, M. Clusters and the New Economics of Competition. Harvard Business Review, Dec. 1998.

PORTER, M. Competição - Estratégias Competitivas Essenciais. 2a Edição. São Paulo: Editora Campus, 1999.

PUU, T. Mathematical Location and Land Use Theory. New York: Springer-Verla, 1997.

REILLY, W. J. The Law of Retail Gravitation. New York: Knickerbocker Press, 1931.

SENE, E.; MOREIRA, J. C. Geografia - Espaço Geográfico e Globalização. São Paulo: Ed. Scipione, 2000 .

SLACK, N. et al. Administração da Produção. São Paulo: Editora Atlas, 1997. 


\section{PRÊMIO GESTÃO EMPRESARIAL- EMPRESA JR - PROBLEMAS E MÉTODOS DECISÓRIOS \\ DE LOCALIZAÇ̃̃O DE EMPRESAS \\ Fábio Ricardo Loureiro Sato}

WESOLOWSKY, G. O.; LOVE, R. F. A Nonlinear Approximation Method for Solving a Generalized Rectangular Distance Weber Problem. Management Science. v.18, p. 656-663, 1972. 